\title{
FIXED POINTS AND CONTINUITY FOR MULTIVALUED MAPPINGS
}

\author{
TROY HICKS and B.E. RHOADES \\ Department of Mathematics \\ University of Missouri at Rolla \\ Rolla, Missouri 65401 \\ Department of Mathematics \\ Indiana University \\ Bloomington, Indiana 47405 \\ (Received July 31, 1990 and in revised form January 11, 1991)
}

\begin{abstract}
Many of the contractive definitions do not require continuity of the map. However, in a previous paper the second author has shown in [1] that, in most cases, the function is continuous at a fixed point. In this paper we show that the same behavior is exhibited for many multivalued mappings.
\end{abstract}

KEY WORDS AND PHRASES. Continuity, fixed point, multivalued mapping. 1980 AMS SUBJECT CLASSIFICATION CODE. 54 H 25

In a recent paper, Rhoades [1], it was verified that, for most contractive definitions, the contractive definition was strong enough to force continuity of the function at a fixed point, even though continuity was neither assumed nor implied by the contractive definition.

The purpose of this paper is to prove that the situation is the same in the multivalued arena.

Before examining the multivalued cases, we shall establish a result, which is of interest in its own right.

PROPOSITION 1. Let $T$ be a selfmap of a complete metric space with a fixed point $p$. Then the following are equivalent:

(a) $T$ is continuous at $p$.

(b) If $\left\{y_{n}\right\}$ is any sequence contained in $X$ with $y_{n} \rightarrow p$, then $\lim d\left(y_{n}, T y_{n}\right)=0$.

PROOF. To show that (a) and (b) are equivalent, suppose that (a) is satisfied. Then $y_{n} \rightarrow p$ implies that $T y_{n} \rightarrow T p=p$, and thus $\lim d\left(y_{n}, T y_{n}\right)=0$.

Conversely, $d\left(T y_{n}, T p\right) \leq d\left(T y_{n}, y_{n}\right)+d\left(y_{n}, p\right)$, so that $\limsup d\left(T y_{n}, T p\right) \leq \lim \sup \left[d\left(T y_{n}, y_{n}\right)+d\left(y_{n}, T p\right)\right]=0$. Then $T$ is continuous at $p$.

In the multivalued case, a multivalued map $T$ has a fixed point $p$ if $p \in T p$. Let $C L(X)$ denote the collection of nonempty closed subsets of $X, D(A, B):=\inf \{d(a, b): a \in A, b \in B\}$. A multivalued map $T:(X, d) \rightarrow(C L(X), D)$ will be said to be continuous at a point $p$ if $\lim _{n} d\left(x_{n}, p\right)=0$ implies that $\lim _{n} D\left(T x_{n}, T p\right)=0$.

PROPOSITION 2. Let $T:(X, d) \rightarrow(C L(X), D)$, with $p$ a fixed point of $T$. Then the following are equivalent : 
(a) $T$ is continuous at $p$,

(b) If $\left\{y_{n}\right\} \subset X$ with $\lim y_{n}=p$, then $\lim D\left(y_{n}, T y_{n}\right)=0$.

Suppose that (a) is satisfied, $D\left(y_{n}, T y_{n}\right) \leq D\left(y_{n}, p\right)+D\left(p, T y_{n}\right) \rightarrow 0$, and (b) is satisfied. Conversely, if (b) holds, then $D\left(T y_{n}, T p\right) \leq D\left(T y_{n}, y_{n}\right)+D\left(y_{n}, p\right) \rightarrow 0$, and (a) is satisfied.

In Proposition 2, we obtain the same conclusions by replacing $C L(X)$ with $B(X)$, the set of all nonempty bounded subsets of $X$, and replacing $D$ by $\delta(A, B)$, where $\delta(A, B):=\sup \{d(a, b)$ : $a \in A, b \in B\}$. We can also replace $C L(X)$ with $C B(X)$, the collection of nonempty closed, bounded subsets of $X$, and replace $D$ with $H$, the Hausdorff metric.

THEOREM 1. Let $F: X \rightarrow B(X), I: X \rightarrow X, I$ continuous, $F, I$ satisfying

$$
\delta(F x, F y) \leq c \max \{\delta(I x, I y), \delta(I x, F x), \delta(I y, F y), \delta(I x, F y), \delta(I y, F x)\}
$$

for all $x, y$ in $X, 0 \leq c<1$. If $F$ and $I$ commute and $I(X) \supseteq F(X)$, then $F$ and $I$ have a unique common fixed point $z, F z=\{z\}$, and $F$ is continuous at $z$.

The fact that $F$ and $I$ have a unique common fixed point comes from Fisher [2]. Although not mentioned in the statement of Theorem 1, Fisher [2] has shown that $I z=\{z\}$. To show that $F$ is continuous at $z$, let $\left\{y_{n}\right\} \subset X, y_{n} \rightarrow z$. From (1),

$$
\delta\left(F y_{n}, z\right) \leq c \max \left\{\delta\left(I y_{n}, I z\right), \delta\left(I y_{n}, F y_{n}\right), \delta(I z, F z), \delta\left(I y_{n}, F z\right), \delta\left(I z, F y_{n}\right)\right\}
$$

Since $y_{n} \rightarrow z$ and $I$ is continuous, $I y_{n} \rightarrow I z=z$. Also, $\delta\left(I y_{n}, F y_{n}\right) \leq \delta\left(I y_{n}, z\right)+\delta\left(z, F y_{n}\right)$. Therefore $\delta\left(F y_{n}, z\right) \leq c\left[\delta\left(I y_{n}, z\right)+\delta\left(z, F y_{n}\right)\right]$, which implies that $\delta\left(F y_{n}, z\right) \leq c\left[\delta\left(I y_{n}, z\right)\right] /(1-c) \rightarrow 0$ as $n \rightarrow \infty$, and $F$ is continuous at $z$.

By setting $I$ equal to the identity map, Theorem 1 is a generalization of the result in Fisher [3].

For an integer $n, x \in X, F^{n}$ is defined inductively by $F^{n}(x)=F\left(F^{n-1}(x)\right)$.

THEOREM 2. Let $F: X \rightarrow B(X)$ satisfying

$$
\delta\left(F^{p} x, F y\right) \leq c \max \left\{\delta\left(F^{r} x, F^{s} y\right), \delta\left(F^{r} x, F^{r^{\prime}} x\right), \delta(y, F y): 0 \leq r, r^{\prime} \leq p, s=0,1\right\}
$$

for all $x, y$ in $X, 0 \leq c<1$ for some fixed integer $p$. If $F$ also maps $B(X)$ into itself, then $F$ has a unique fixed point $z, F z=\{z\}$, and $F$ is continuous at $z$.

PROOF. The fact that $F$ has a unique fixed point $z$ and that $F z=\{z\}$ comes from Fisher [4]. Let $\left\{y_{n}\right\} \subset X, y_{n} \rightarrow z$. In (2) set $x=z, y=y_{n}$ to get

$$
\begin{aligned}
\delta\left(F^{p} z, F y_{n}\right) & \leq c \max \left\{\delta\left(F^{r} z, F^{s} y_{n}\right), \delta\left(F^{r} z, F^{r^{\prime}} z\right), \delta\left(y_{n}, F y_{n}\right): 0 \leq r, r^{\prime} \leq p, s=0,1\right\} \\
& =c \max \left\{\delta\left(z, y_{n}\right), \delta\left(z, F y_{n}\right), \delta\left(y_{n}, F y_{n}\right)\right\} .
\end{aligned}
$$

Since $\delta\left(y_{n}, F y_{n}\right) \leq \delta\left(z, y_{n}\right)+\delta\left(z, F y_{n}\right)$, the above inequality becomes $\delta\left(z, F y_{n}\right) \leq c\left[\delta\left(z, y_{n}\right)+\right.$ $\left.\delta\left(z, F y_{n}\right)\right]$, which implies that $\delta\left(z, F y_{n}\right) \leq c\left[\delta\left(z, y_{n}\right)\right] /(1-c) \rightarrow 0$ as $n \rightarrow \infty$. Thus $F$ is continuous at $z$.

Theorem 2 also generalizes the corresponding result in Fisher [4].

For a metric space $X, N(\varepsilon, A):=\{x \in X: d(x, a)<\varepsilon$ for some $a \in A \in C L(X), \varepsilon>0\}$. The Hausdorff metric $H$ is defined by $H(A, B)=\inf \{\varepsilon>0: A \subseteq N(\varepsilon, B)$ and $B \subseteq N(\varepsilon, A)\}$, if the infimum exists, and $H(A, B)=\infty$ otherwise. An equivalent definition of $H$ is

$$
H(A, B)=\max \left\{\sup _{x \in B} d(x, A), \sup _{x \in A} d(x, B)\right\} .
$$


THEOREM 3. Let $F_{1}, F_{2}: X \rightarrow C B(X)$ satisfying

$$
H\left(F_{1} x, F_{2} y\right) \leq a_{1} \delta\left(x, F_{1} x\right)+a_{2} \delta\left(y, F_{2} y\right)+a_{3} \delta\left(x, F_{2} y\right)+a_{4} \delta\left(y, F_{1} x\right)+a_{5} d(x, y)
$$

for all $x, y$ in $X$, where the $a_{1} \geq 0, \sum_{t=1}^{5} a_{i}<1$ and $a_{1}=a_{2}$ or $a_{3}=a_{4}$. If $z$ is a common fixed point of $F_{1}$ and $F_{2}$ such that $F_{1} z=\{z\}$ or $F_{2} z=\{z\}$, then $z$ is the unique common fixed point of $F_{1}$ and $F_{2}$. Moreover, $F_{1}$ and $F_{2}$ are continuous at $z$.

PROOF. The conclusions about the fixed point $z$ come from Mendaglio and Dube [5]. We first observe that the hypotheses of the theorem implies that both $F_{1} z=F_{2} z=\{z\}$. For, suppose that $F_{2} z=\{z\}$. Then, in (3) with $x=y=z$, we have

$$
H\left(F_{1} z, F_{2} z\right) \leq a_{1} \delta\left(z, F_{1} z\right)+a_{2} \delta\left(z, F_{2} z\right)+a_{3} \delta\left(z, F_{2} z\right)+a_{4} \delta\left(z, F_{1} z\right)+a_{5} \delta(z, z),
$$

and $H\left(F_{1} z,\{z\}\right) \leq\left(a_{1}+a_{4}\right) \delta\left(z, F_{1} z\right)$. But $H\left(F_{1} z,\{z\}\right)=\delta\left(z, F_{1} z\right)$. Therefore $F_{1} z=\{z\}$. Similarly, $F_{1} z=\{z\}$ implies $F_{2} z=\{z\}$.

To prove continuity, let $\left\{y_{n}\right\} \subset X, y_{n} \rightarrow z$. In (3) set $x=y_{n}, y=z$ to get

$$
H\left(F_{1} y_{n}, F_{2} z\right) \leq a_{1} \delta\left(y_{n}, F_{1} y_{n}\right)+a_{2} \delta\left(z, F_{2} z\right)+a_{3} \delta\left(y_{n}, F_{2} z\right)+a_{4} \delta\left(z, F_{1} y_{n}\right)+a_{5} d\left(y_{n}, z\right) .
$$

Thus

$$
H\left(F_{1} y_{n}, z\right)=\delta\left(F_{1} y_{n}, z\right) \leq \frac{\left(a_{1}+a_{2}+a_{3}\right)}{1-a_{1}-a_{4}} d\left(y_{n}, z\right),
$$

which tends to 0 as $n \rightarrow \infty$, and $F_{1}$ is continuous at $z$.

Setting $x=z$ and $y=y_{n}$ in (3) leads to the result that $F_{2}$ is continuous at $z$.

THEOREM 4. Let $F, G: X \rightarrow B(X)$

$$
\delta(F x, G y) \leq \alpha_{1}(p) \delta(x, F x)+\alpha_{2}(p) \delta(y, G y)+\alpha_{3}(p) \delta(x, G y)+\alpha_{4}(p) \delta(y, F x)+\alpha_{5}(p) d(x, y)
$$

for all $x, y$ in $X$, where $p:=\delta(F x, G y)>0$, and where each $\alpha_{i}:(0, \infty) \rightarrow[0,1)$ is a decreasing function such that $\left(\alpha_{1}+\alpha_{2}+2 \alpha_{3}+2 \alpha_{4}+\alpha_{5}\right)(t)<1$ for each $t>0$. Then there exists a unique point $z$ in $X$ satisfying $F z=G z=\{z\}, F$ and $G$ have a unique common fixed point in $X$, and $F$ and $G$ are continuous at $z$.

That $z$ is the unique common fixed point of $F$ and $G$ follows from Samanta and Baisnab [6]. To prove continuity, let $\left\{y_{n}\right\} \subset X, y_{n} \rightarrow z$. From (4), with $x=y_{n}, y=z$, we have

$$
\delta\left(F y_{n}, G z\right) \leq \alpha_{1}(p) \delta\left(y_{n}, F y_{n}\right)+\alpha_{2}(p) \delta(z, G z)+\alpha_{3}(p) \delta\left(y_{n}, G z\right)+\alpha_{4}(p) \delta\left(z, F y_{n}\right)+\alpha_{5}(p) d\left(y_{n}, z\right)
$$

or

$$
\delta\left(F y_{n}, z\right) \leq\left(\alpha_{1}(p)+\alpha_{4}(p)\right) \delta\left(z, F y_{n}\right)+\left(\alpha_{1}(p)+\alpha_{3}(p)+\alpha_{5}(p)\right) d\left(y_{n}, z\right)
$$

i.e.,

$$
\delta\left(F y_{n}, z\right) \leq \frac{\alpha_{1}(p)+\alpha_{3}(p)+\alpha_{5}(p)}{1-\alpha_{1}(p)-\alpha_{4}(p)} d\left(y_{n}, z\right)
$$


which tends to 0 as $n \rightarrow \infty$, and $F$ is continuous at $z$. A similar argument shows that $G$ is continuous at $z$.

THEOREM 5. Let $F, G: X \rightarrow B(X)$ satisfying

$$
\delta(F x, G y) \leq \alpha_{1} \delta(x, F x)+\alpha_{2} \delta(y, G y)+\alpha_{3} \delta(x, G y)+\alpha_{4} \delta(y, F x)+\alpha_{5} d(x, y)
$$

for all $x, y$ in $X$, where the $\alpha_{i} \geq 0, \alpha_{1}+\alpha_{2}+2 \alpha_{4}+\alpha_{5}<1$ and $\alpha_{1}+\alpha_{4}<1$. Then $F$ and $G$ have a common fixed point. If, further, $\alpha_{3}+\alpha_{4}+\alpha_{5}<1$, then $F z=G z=\{z\}$ and $z$ is the unique common fixed point of $F$ and $G$. Moreover, if $F$ and $G$ have a unique common fixed point $z$, then $F$ and $G$ are continuous at $z$.

The fixed point properties come from Theorem 2 of Dixit [7]. To prove continuity, let $\left\{y_{n}\right\} \subset X, y_{n} \rightarrow z$ and set $x=y_{n}, y=z$ in (5) to get

$$
\delta\left(F y_{n}, G z\right) \leq \alpha_{1} \delta\left(y_{n}, F y_{n}\right)+\alpha_{2} \delta(z G z)+\alpha_{3} \delta\left(y_{n}, G z\right)+\alpha_{4} \delta\left(z, F y_{n}\right)+\alpha_{5} d\left(y_{n}, z\right)
$$

Thus

$$
\delta\left(F y_{n}, z\right) \leq\left(\alpha_{1}+\alpha_{4}\right) \delta\left(z, F y_{n}\right)+\left(\alpha_{1}+\alpha_{3}+\alpha_{5}\right) d\left(y_{n}, z\right)
$$

or,

$$
\delta\left(F y_{n}, z\right) \leq \frac{\alpha_{1}+\alpha_{2}+\alpha_{3}}{1-\alpha_{1}-\alpha_{4}} d\left(y_{n}, z\right),
$$

which tends to 0 as $n \rightarrow \infty$, and $F$ is continuous at $z$. A similar argument shows that $G$ is continuous at $z$.

THEOREM 6. Let $F, G: X \rightarrow B(X)$ satisfying

$$
\delta(F x, G y) \leq c \max \{\delta(x, F x), \delta(y, G y), \delta(x, G y), \delta(y, F x), d(x, y)\}
$$

for all $x, y$ in $X, 0 \leq c<1$. Then $F$ and $G$ have a unique common fixed point $z, F z=G z=\{z\}$, and $F$ and $G$ are continuous at $z$.

The existence and uniqueness of the fixed point come from Fisher [8]. To prove continuity, let $\left\{y_{n}\right\} \subset X, y_{n} \rightarrow z$ and set $x=y_{n}, y=z$ in (6) to get

$$
\delta\left(F y_{n}, G z\right) \leq c \max \left\{\delta\left(y_{n}, F y_{n}\right), \delta(z, G z), \delta\left(y_{n}, G z\right), \delta\left(z, F y_{n}\right), d\left(y_{n}, z\right)\right\}
$$

or, since $\delta\left(y_{n}, F y_{n}\right) \leq \delta\left(y_{n}, z\right)+\delta\left(z, F y_{n}\right), \delta\left(F y_{n}, z\right) \leq c\left[\delta\left(y_{n}, z\right)+\delta\left(z, F y_{n}\right)\right]$, which implies that $\delta\left(F y_{n}, z\right) \leq c\left[\delta\left(y_{n}, z\right) /(1-c)\right] \rightarrow 0$ as $n \rightarrow \infty$, and $F$ is continuous at $z$.

A similar proof show that $G$ is continuous at $z$.

THEOREM 7. Let $F, G: X \rightarrow B(X), X$ bounded, $F$ continuous, $F$ commutes with $G$, and satisfying

$$
\begin{array}{r}
\delta\left(F^{p} G^{p} x, G y\right) \leq c \max \left\{\delta\left(F^{r} G^{s} x, G^{i} y\right), \delta\left(F^{r} G^{s} x, F^{r^{\prime}} G^{s^{\prime}} x\right), \delta(y, G y)\right. \\
\left.: 0 \leq r, r^{\prime}, s, s^{\prime} \leq p ; i=0,1\right\}
\end{array}
$$

for all $x, y$ in $X, 0 \leq c<1, p$ a fixed positive integer. Then $F$ and $G$ have a unique common fixed point $z, F z=G z=\{z\}$, and $G$ is continuous at $z$. 
The existence and uniqueness of the fixed point come from Theorem 2 of Fisher [9]. To prove the continuity of $G$, let $\left\{y_{n}\right\} \subset X, y_{n} \rightarrow z$, and set $x=z, y=y_{n}$ in (7) to get

$$
\begin{array}{r}
\delta\left(F^{p} G^{p} z, G y_{n}\right) \leq c \max \left\{\delta\left(F^{r} G^{s} z, G^{i} y_{n}\right), \delta\left(F^{r} G^{s} z, F^{r^{\prime}} G^{s^{\prime}} z\right), \delta\left(y_{n}, G y_{n}\right)\right. \\
\left.: 0 \leq r, r^{\prime}, s, s^{\prime} \leq p ; i=0,1\right\}
\end{array}
$$

or,

$$
\delta\left(z, G y_{n}\right) \leq c \max \left\{d\left(z, y_{n}\right), \delta\left(y_{n}, G y_{n}\right)\right\}
$$

Since $\delta\left(y_{n}, G y_{n}\right) \leq \delta\left(z, G y_{n}\right)+d\left(z, y_{n}\right), \delta\left(z, G y_{n}\right) \leq c\left[\delta\left(z, G y_{n}\right)+d\left(z, y_{n}\right)\right]$, which implies that $\delta\left(z, G y_{n}\right) \leq c\left[d\left(y_{n}, z\right) /(1-c)\right] \rightarrow 0$ as $n \rightarrow \infty$, and $G$ is continuous at $z$.

THEOREM 8. Let $F, G: X \rightarrow B(X)$ satisfying

$$
\delta(F x, G y) \leq c \max \{d(x, y), \delta(x, G y), \delta(y, F x)\}
$$

for each $x, y$ in $X, 0 \leq c<1$. Then $F$ and $G$ have a unique common fixed point $z, F z=G z=$ $\{z\}$, and $F$ and $G$ are continuous at $z$.

The existence and uniqueness of the fixed point follow from Fisher [10]. To prove the continuity of $G$, let $\left\{y_{n}\right\} \subset X, y_{n} \rightarrow z$, and set $x=y_{n}, y=z$ in (8) to get

$$
\delta\left(F y_{n}, G z\right) \leq c \max \left\{d\left(y_{n}, z\right), \delta\left(y_{n}, G z\right), \delta\left(z, F y_{n}\right)\right\}
$$

Thus $\delta\left(F y_{n}, z\right) \leq c d\left(y_{n}, z\right) \rightarrow 0$ as $n \rightarrow \infty$, and $F$ is continuous at $z$. Setting $x=z, y=y_{n}$ in (8) leads to the fact that $G$ is continuous at $z$.

THEOREM 9. Let $F, G: X \rightarrow B(X), I, J,: X \rightarrow X$ satisfying

$$
\delta(F x, G y) \leq c \max \{d(I x, J y), \delta(I x, G y), \delta(J y, F x)\}
$$

for all $x, y$ in $X, 0 \leq c<1$. If $F$ commutes with $I$ and $G$ commutes with $J, F(X) \subseteq$ $I(X), G(X) \subseteq J(X)$ and, if $F$ or $I$ and $G$ or $J$ are continuous, then $F, G, I$, and $J$, have a unique common fixed point $z$. Further, $F z=G z=\{z\}$, and $z$ is the unique common fixed point of $F$ and $I$ and $G$ and $J$. If $I$ and $J$ are continuous, then $F$ and $G$ are continuous at $z$. If $F$ and $G$ are continuous, then $I$ and $J$ are continuous at $z$.

PROOF. The existence and uniqueness of $z$ follow from Theorem 1 of Fisher [11]. Suppose that $I$ and $J$ are continuous. Let $\left\{y_{n}\right\} \subset X, y_{n} \rightarrow z$, and set $x=y_{n}, y=z$ in (9) to get

$$
\delta\left(F y_{n}, G z\right) \leq c \max \left\{d\left(I y_{n}, J z\right), \delta\left(I y_{n}, G z\right), \delta\left(J z, F y_{n}\right)\right\}
$$

Thus $\delta\left(F y_{n}, z\right) \leq c d\left(I y_{n}, z\right) \rightarrow 0$ as $n \rightarrow \infty$, and $F$ is continuous at $z$.

Now set $x=z, y=y_{n}$ in (9) to get

$$
\delta\left(F z, G y_{n}\right) \leq c \max \left\{d\left(I z, J y_{n}\right), \delta\left(I z, G y_{n}\right), \delta\left(J y_{n}, F z\right)\right\}
$$

or $\delta\left(z, G y_{n}\right) \leq c d\left(z, J y_{n}\right) \rightarrow 0$ as $n \rightarrow \infty$, and $G$ is continuous at $z$.

A similar argument shows that the assumption that $F$ and $J$ are continuous leads to the continuity of $I$ and $J$ at $z$. 
The special case of Theorem 9 in which $I$ is the identity map on $X$ yields the result in Fisher [12].

THEOREM 10. Let $F, G: X \rightarrow B(X), I, J,: X \rightarrow X$ satisfying

$$
\delta(F x, G y) \leq c \max \{d(I x, J y), \delta(I x, F x), \delta(J y, G y)\}
$$

for all $x, y$ in $X, 0 \leq c<1$. If $F$ commutes with $I$ and $G$ commutes with $J, G(X) \subseteq$ $I(X), F(X) \subseteq J(X)$ and, if $I$ or $J$ is continuous, then $F, G, I$, and $J$ have a unique common fixed point $z$. Further, $F z=G z=\{z\}$, and $z$ is the unique common fixed point of $F, G, I$, and $J$. Further, the continuity of $I$ implies that $F$ is continuous at $z$, and the continuity of $J$ implies that $G$ is continuous at $z$.

The existence and uniqueness of $z$ follows from Theorem 1 of Fisher [13]. Suppose that $I$ is continuous. Let $\left\{y_{n}\right\} \subset X, y_{n} \rightarrow z$, and set $x=y_{n}, y=z$ in (10) to get

$$
\delta\left(F y_{n}, G z\right) \leq c \max \left\{d\left(I y_{n}, J z\right), \delta\left(I y_{n}, F y_{n}\right), \delta(J z, G z)\right\}
$$

i.e.,

$\delta\left(F y_{n}, z\right) \leq c \max \left\{d\left(I y_{n}, z\right), \delta\left(I y_{n}, F y_{n}\right)\right\}$, which, since $\delta\left(I y_{n}, F y_{n}\right) \leq \delta\left(I y_{n}, z\right)+\delta\left(z, F y_{n}\right)$, implies that $\delta\left(F y_{n}, z\right) \leq c\left[\delta\left(I y_{n}, z\right)+\delta\left(z, F y_{n}\right)\right] \rightarrow 0$ as $n \rightarrow \infty$, and $F$ is continuous at $z$.

The assumption that $J$ is continuous leads to the continuity of $G$ at $z$.

The special case of Theorem 10 with $I=J=I_{X}$ yields the result of Fisher [10], and the continuity of both $F$ and $G$ at $z$.

THEOREM 11. Let $F, G: X \rightarrow B(X), I, J,: X \rightarrow X$ satisfying

$$
\delta\left(F^{p} x, G y\right) \leq c \max \left\{\delta\left(F^{r} x, G y\right), \delta\left(F^{r} x, y\right): 0 \leq r \leq p\right\}
$$

for all $x, y$ in $X, 0 \leq c<1, p$ a fixed positive integer. If $F$ also maps $B(X)$ into itself, then $F$ and $G$ have a unique common fixed point $z$. Further, $z$ is the unique fixed point of $F$ and $G, F z=G z=\{z\}$, and $G$ is continuous at $z$.

The existence and uniqueness of $z$ come from Theorem 2 in Fisher [14]. To prove the continuity of $F$, let $\left\{y_{n}\right\} \subset X, y_{n} \rightarrow z$, and set $x=z, y=y_{n}$ in (11) to get

$$
\delta\left(F^{p} z, G y_{n}\right) \leq c \max \left\{\delta\left(F^{r} z, G y_{n}\right), \delta\left(F^{r} z, y_{n}\right): 0 \leq r \leq p\right\}
$$

i.e.,

$$
\delta\left(z, G y_{n}\right) \leq c \max \left\{\delta\left(z, G y_{n}\right), \delta\left(z, y_{n}\right)\right\},
$$

which implies that $\delta\left(z, G y_{n}\right) \leq c \delta\left(z, y_{n}\right) \rightarrow 0$ as $n \rightarrow \infty$, and $G$ is continuous at $z$.

A similar calculation verifies that $G$ is continuous at $z$.

We now establish continuity for multivalued mappings with metric defined by the Hausdorff metric.

THEOREM 12. Let $T: X \rightarrow C B(X)$ satisfying

$$
\begin{gathered}
H(T x, T y) \leq a(x, y) D(x, T x)+a^{\prime}(x, y) D(y, T y)+b(x, y) D(x, T y)+ \\
b^{\prime}(x, y) D(y, T x)+c(x, y) d(x, y)
\end{gathered}
$$

for all $x, y$ in $X, a, a^{\prime}, b, b^{\prime}, c: X \times X \rightarrow \mathbf{R}+$ and $\left(a+a^{\prime}+b+b^{\prime}+c\right)(x, y)<1$ for all $x, y$ in $X$. If 


$$
\limsup _{d(x, y) \rightarrow 0}\left(a+a^{\prime}+b+b^{\prime}+c\right)(x, y)<1,
$$

then for each $x_{o}$ in $X$ there exists a sequence of iterates converging to a fixed point $z$ of $T$, and $T$ is continuous at $z$.

The existence of a fixed point is a consequence of Garegnani and Massa [15]. To prove continuity, let $\left\{y_{n}\right\} \subset X, y_{n} \rightarrow z$, and set $x=y_{n}, y=z$ in (12) to get

$$
\begin{aligned}
H\left(T y_{n}, T z\right) \leq a\left(y_{n}, z\right) D\left(y_{n}, T y_{n}\right) & +a^{\prime}\left(y_{n}, z\right) D(z, T z)+b\left(y_{n}, z\right) D\left(y_{n}, T z\right) \\
& +b^{\prime}\left(y_{n}, z\right) D\left(z, T y_{n}\right)+c\left(y_{n}, z\right) d\left(y_{n}, z\right) .
\end{aligned}
$$

Thus,

$$
\begin{aligned}
D\left(T y_{n}, z\right) \leq H\left(T y_{n}, T z\right) & \leq a\left(d\left(y_{n}, z\right)+D\left(z, T y_{n}\right)\right)+b D\left(y_{n}, T z\right) \\
& +b^{\prime} D\left(z, T y_{n}\right)+c d\left(y_{n}, z\right)
\end{aligned}
$$

or

$$
D\left(T y_{n}, z\right) \leq \frac{(a+c) d\left(y_{n}, z\right)+b D\left(y_{n}, T z\right)}{1-a-b^{\prime}}
$$

which tends to 0 as $n \rightarrow \infty$, since $\lim \left(1-a-b^{\prime}\right)>0$, and $\lim _{n} D\left(T y_{n}, z\right)=0$, which implies that $\lim _{n} D\left(y_{n}, T y_{n}\right)=0$. Taking the limit as $n \rightarrow \infty$ of the inequality involving $H$ yields $\lim _{n} H\left(T y_{n}, T z\right)=0$, and $T$ is continuous at $z$.

THEOREM 13. Let $T: X \rightarrow C L(X), f: X \rightarrow X$ such that $T X \subset f X, f X$ is $(T, f)$ orbitally complete and

$$
H(T x, T y) \leq q \max \{d(f x, f y), D(f x, T x), D(f y, T y),[D(f x, T y)+D(f y, T x)] / 2\}
$$

for all $x, y$ in $X, 0<q<1$. Then $T$ and $f$ have a coincidence point; i.e., there exists a $z$ in $X$ such that $f z \in T z$.

COROLLARY 1 . Let $f$ be the identity map on $X$. Then, under the hypotheses of Theorem 13, $T$ has a fixed point $z$, and $T$ is continuous at $z$.

The fact that $T$ has a fixed point comes from Singh and Kulshrestha [16]. To prove continuity, let $\left\{y_{n}\right\} \subset X, y_{n} \rightarrow z$, and set $x=y_{n}, y=z$ in (13) to get

$$
H\left(T y_{n}, T z\right) \leq q \max \left\{d\left(y_{n}, z\right), D\left(y_{n}, T y_{n}\right), D(z, T z),\left[D\left(y_{n}, T z\right)+D\left(z, T y_{n}\right)\right] / 2\right\}
$$

Thus

$$
\begin{aligned}
D\left(T y_{n}, z\right) & \leq q \max \left\{d\left(y_{n}, z\right), D\left(y_{n}, T y_{n}\right), 0,\left[D\left(y_{n}, T z\right)+D\left(z, T y_{n}\right)\right] / 2\right\} \\
& \leq \max \left\{q d\left(y_{n}, z\right), \frac{q}{1-q} D\left(y_{n}, z\right), \frac{q}{2-q} D\left(y_{n}, T z\right)\right\} \rightarrow 0 \text { as } n \rightarrow \infty
\end{aligned}
$$

and $\lim _{n} D\left(T y_{n}, z\right)=0$, which implies that $\lim _{n} D\left(y_{n}, T y_{n}\right)=0$. Taking the limit as $n \rightarrow \infty$, in the inequality involving $H$, yields $\lim _{n} H\left(T y_{n}, T z\right)=0$, and $T$ is continuous at $z$. 
The fixed point portion of Corollary 1 is essentially due to Ciric [17]. The theorem of Ciric also contains a result of Reich [18] as a special case.

Kaneko [19] proves the Ciric result under the weaker conditions that $X$ be a reflexive space and the range of $T$ is the family of all nonempty weakly compact subsets of $X$. He is apparently unaware that the two standard definitions of the Hausdorff metric are equivalent.

Theorems 1 and 2 in Czerwick [20] are special cases of Corollary 1, as are Theorem 1 of Iseki [21] and Theorem 1 of Ray [22].

THEOREM 14 . Let $(X, d)$ be a complete metrically convex metric space, $K$ a nonempty closed subset of $X, T: X \rightarrow C B(X)$ such that there exist $\alpha, \beta, \gamma \geq 0, \alpha+2 \beta+2 \gamma<1$ such that for all $x, y$ in $X$,

$$
H(T x, T y) \leq \alpha d(x, y)+\beta\{D(x, T x)+D(y, T y)\}+\gamma\{D(x, T y)+D(y, T x)\} .
$$

If for each $x \in \partial K, T x \subset K$ and $(\alpha+\beta+\gamma)(1+\beta+\gamma) /(1-\beta-\gamma)^{2}<1$, then there exists a $z$ in $K$ with $z \in T z$. Moreover $T$ is continuous at $z$.

The existence of $z$ is Theorem 1 of Itoh [23]. To show continuity, let $\left\{y_{n}\right\} \subset X, y_{n} \rightarrow z$, and set $x=y_{n}, y=z$ in (14) to get

$$
H\left(T y_{n}, T z\right) \leq \alpha d\left(y_{n}, z\right)+\beta\left\{D\left(y_{n}, T y_{n}\right)+D(z, T z)\right\}+\gamma\left\{D\left(y_{n}, T z\right)+D\left(z, T y_{n}\right)\right\}
$$

Then

$$
D\left(z, T y_{n}\right) \leq H\left(T y_{n}, T z\right) \leq \alpha d\left(y_{n}, z\right)+\beta\left\{D\left(y_{n}, z\right)+D\left(z, T y_{n}\right)\right\}+\gamma\left\{D\left(y_{n}, T z\right)+D\left(z, T y_{n}\right)\right\}
$$

or,

$$
D\left(z, T y_{n}\right) \leq \frac{(\alpha+\beta) d\left(y_{n}, z\right)+\gamma D\left(y_{n}, T z\right)}{1-\beta-\gamma} \rightarrow 0 \text { as } n \rightarrow \infty,
$$

and $\lim _{n} D\left(z, T y_{n}\right)=0$, which implies that $\lim _{n} D\left(y_{n}, T y_{n}\right)=0$. Now take the limit as $n \rightarrow \infty$ in the inequlality for $H$ to get $\lim _{n} H\left(T z, T y_{n}\right)=0$, and $T$ is continuous at $z$.

THEOREM 15. Let $(X, d)$ be a complete bounded metric space, $F_{\imath}: X \rightarrow C L(X), i=1,2$ satisfying

$$
H\left(F_{1} x, F_{2} y\right) \leq a_{1} D\left(x, F_{1} x\right)+a_{2} D\left(y, F_{2} y\right)+a_{3} D\left(y, F_{1} x\right)+a_{4} D\left(x, F_{2} y\right)+a_{5} d(x, y)
$$

for all $x, y$ in $X, a_{i} \geq 0, \Sigma_{i=1}^{5} a_{i}<1$ and $a_{1}=a_{2}$ or $a_{3}=a_{4}$. Then $F_{1}$ and $F_{2}$ have a common fixed point $z$. Moreover $F_{1}$ and $F_{2}$ are continuous at $z$.

The existence of $z$ comes from Theorem 1 of Bose and Mukherjee [24]. To prove continuity of $F_{1}$, let $\left\{y_{n}\right\} \subset X, y_{n} \rightarrow z$, and set $x=y_{n}, y=z$ in (15) to get

$$
H\left(F_{1} y_{n}, F_{2} z\right) \leq a_{1} D\left(y_{n}, F_{1} y_{n}\right)+a_{2} D\left(z, F_{2} z\right)+a_{3} D\left(z, F_{1} y_{n}\right)+a_{4} D\left(y_{n}, F_{2} z\right)+a_{5} d\left(y_{n}, z\right) .
$$

Setting $x=y=z$ in (15) yields the fact that $F_{1} z=F_{2} z$. Thus

$$
D\left(F_{1} y_{n}, z\right) \leq H\left(F_{1} y_{n}, F_{1} z\right) \leq\left(a_{1}+a_{3}\right) D\left(z, F_{1} y_{n}\right)+a_{4} D\left(y_{n}, F_{2} z\right)+\left(a_{1}+a_{5}\right) d\left(y_{n}, z\right)
$$


and

$$
D\left(z, F_{1} y_{n}\right) \leq \frac{a_{4} D\left(y_{n}, F_{2} z\right)+\left(a_{1}+a_{5}\right) d\left(y_{n}, z\right)}{1-a_{1}-a_{3}},
$$

which leads to the facts that $\lim _{n} D\left(z, F_{1} y_{n}\right)=0$ and $\lim _{n} D\left(y_{n}, F_{1} y_{n}\right)=0$. Taking the limit of the inequality for $H$, and using the fact that $F_{1} z=F_{2} z$, yields $\lim _{n} H\left(F_{1} y_{n}, F_{2} z\right)=0$, and $F_{1}$ is continuous at $z$.

Similarly, $F_{2}$ is continuous at $z$.

THEOREM 16. Let $(X, d)$ be a complete metrically convex metric space, $K$ a nonempty closed subset of $X$. Let $S, T: K \rightarrow C B(X)$ satisfying

$$
H(S x, T y) \leq \alpha d(x, y)+\beta\{D(x, S x)+D(y, T y)\}+\gamma\{D(x, T y)+D(y, S x)\}
$$

for all $x, y$ in $X, \alpha, \beta, \gamma \geq 0$ with $\alpha+2 \beta+2 \gamma<1$. If for each $x \in \partial K, S(x) \subset K, T(x) \subset K$ and $(\alpha+\beta+\gamma)(1+\beta+\gamma) /(1-\beta-\gamma)^{2}<1$, then there exists a $z$ in $K$ with $z \in T z$ and $z \in S z$. Also $S$ and $T$ are continuous at $z$.

The properties of $z$ come from Theorem 3.1 of Khan [24]. To establish the continuity of $S$, let $\left\{y_{n}\right\} \subset X, y_{n} \rightarrow z$, and set $x=y_{n}, y=z$ in (16) to get

$$
H\left(S y_{n}, T z\right) \leq \alpha d\left(y_{n}, z\right)+\beta\left\{D\left(y_{n}, S y_{n}\right)+D(z, T z)\right\}+\gamma\left\{D\left(y_{n}, T z\right)+D\left(z, S y_{n}\right)\right\}
$$

Thus

$$
D\left(S y_{n}, z\right) \leq H\left(S y_{n}, T z\right)=\alpha d\left(y_{n}, z\right)+\beta D\left(y_{n}, S y_{n}\right)+\gamma\left\{D\left(y_{n}, T z\right)+D\left(z, S y_{n}\right)\right\}
$$

or,

$$
D\left(S y_{n}, z\right) \leq \frac{(\alpha+\beta) d\left(y_{n}, z\right)+\gamma D\left(y_{n}, T z\right)}{1-\beta-\gamma},
$$

which implies that $\lim _{n} D\left(S y_{n}, z\right)=0$, and thus that $\lim _{n} D\left(y_{n}, S y_{n}\right)=0$. Setting $x=y=z$ in (16) yields $S z=T z$. Substituting into the inequality for $H$ yields

$$
H\left(S y_{n}, T z\right)=H\left(S y_{n}, S z\right) \leq \alpha d\left(y_{n}, z\right)+\beta D\left(y_{n}, S y_{n}\right)+\gamma\left\{D\left(y_{n}, S z\right)\right\}+D\left(z, S y_{n}\right),
$$

which impies that $\lim _{n} H\left(S y_{n}, S z\right)=0$, and $S$ is continuous at $z$.

A similar calculation verifies that $T$ is continuous at $z$.

THEOREM 17. Let $T_{n}: X \rightarrow C B(X)$ satisfying

$$
\begin{gathered}
\left\{H\left(T_{1} x, T_{n} y\right)\right\}^{2} \leq k \max \left\{D\left(x, T_{1} x\right) D\left(y, T_{n} y\right), D\left(x, T_{n} y\right) D\left(y, T_{1} x\right), D\left(x, T_{1} x\right) D\left(x, T_{n} y\right),\right. \\
\left.D\left(y, T_{1} x\right) D\left(y, T_{n} y\right), d^{2}(x, y)\right\}
\end{gathered}
$$

for all $x, y$ in $X, n \geq 2,0 \leq k<1 / 2$. Then $\left\{T_{n}\right\}$ has a common fixed point and $F\left(T_{1}\right)=$ $F\left(T_{n}\right), n>1$, where $F(T)$ denotes the fixed point set of $T$. Moreover the $\left\{T_{n}\right\}$ are continuous at each fixed point.

The conclusion concerning the fixed points follows from Theorem 3 of Popa [26]. To prove continuity, let $\left\{y_{n}\right\} \subset X, y_{n} \rightarrow z$, and set $x=z, y=y_{k}$ in (17) to get 


$$
\begin{gathered}
\left\{H\left(T_{1} z, T_{n} y_{k}\right)\right\}^{2} \leq k \max \left\{D\left(z, T_{1} z\right) D\left(y_{k}, T_{n} y_{k}\right), D\left(z, T_{n} y_{k}\right) D\left(y_{k}, T_{1} z\right), D\left(z, T_{1} z\right) D\left(z, T_{n} y_{k}\right)\right. \\
\left.D\left(y_{k}, T_{1} z\right) D\left(y_{k}, T_{n} y_{k}\right), d^{2}\left(z, y_{k}\right)\right\}
\end{gathered}
$$

or

$$
\left\{H\left(T_{1} z, T_{n} y_{k}\right)\right\}^{2} \leq k \max \left\{0, D\left(z, T_{n} y_{k}\right) D\left(y_{k}, T_{1} z\right), 0, D\left(y_{k}, T_{1} z\right) D\left(y_{k}, T_{n} y_{k}\right), d^{2}\left(z, y_{k}\right)\right\}
$$

Setting $x=y=z$ in (17) yields $T_{1} z=T_{n} z$. Substituting in the above inequality yields $\limsup \left\{H\left(T_{n} z, T_{n} y_{k}\right)\right\} 2=0$ and each $T_{n}$ is continuous at $z$.

THEOREM 18. Let $(X, d)$ be a complete metric space, $T_{1}, T_{2}: X \rightarrow C B(X)$ satisfying

$$
H^{m}\left(T_{1} x, T_{2} y\right) \leq c \frac{d^{p}\left(x, T_{1} x\right)+d^{p}\left(y, T_{2} y\right)}{\delta^{p-m}\left(x, T_{1} x\right)+\delta^{p-m}\left(y, T_{2} y\right)}
$$

for each $x, y$ in $X$ such that $\delta^{p-m}\left(x, T_{1} x\right)+\delta^{p-m}\left(y, T_{2} y\right) \neq 0,0<c<1, m \geq 1, p \geq 2, m<p$. Then $T_{1}$ and $T_{2}$ have common fixed points. Moreover $T_{1}$ and $T_{2}$ are continuous at each fixed point.

The fact that $T_{1}$ and $T_{2}$ have fixed points is Theorem 2 of Popa [27]. To establish continuity, let $z$ be a common fixed point of $T_{1}$ and $T_{2}$ and let $\left\{y_{n}\right\} \subset X, y_{n} \rightarrow z$, and set $x=z, y=y_{n}$ in (18) to get

$$
\begin{aligned}
H^{m}\left(T_{1} z, T_{2} y_{n}\right) & \leq c \frac{d^{p}\left(z, T_{1} z\right)+d^{p}\left(y_{n}, T_{2} y_{n}\right)}{\delta^{p-m}\left(z, T_{1} z\right)+\delta^{p-m}\left(y_{n}, T_{2} y_{n}\right)} \\
& =c \frac{d^{p}\left(y_{n}, T_{2} y_{n}\right)}{\delta^{p-m}\left(y_{n}, T_{2} y_{n}\right)} \leq c d^{m}\left(y_{n}, T_{2} y_{n}\right)
\end{aligned}
$$

since $d\left(y_{n}, T_{2} y_{n}\right) \leq \delta\left(y_{n}, T_{2} y_{n}\right)$. Therefore

$$
\begin{aligned}
D\left(z, T_{2} y_{n}\right) \leq H\left(T_{1} z, T_{2} y_{n}\right) & \leq c^{1 / m} d\left(y_{n}, T_{2} y_{n}\right)=c^{1 / m} D\left(y_{n}, T_{2} y_{n}\right) \\
& \leq c^{1 / m}\left[D\left(y_{n}, z\right)+D\left(z, T_{2} y_{n}\right)\right]
\end{aligned}
$$

or, $D\left(z, T_{2} y_{n}\right) \leq c^{1 / m}\left[D\left(y_{n}, z\right)\right] /(1-c) \rightarrow 0$ as $n \rightarrow \infty$, and $\lim _{n} D\left(z, T_{2} y_{n}\right)=0$. Also, $\lim _{n} D\left(y_{n}, T_{2} y_{n}\right)=0$.

If $\delta^{p-m}\left(z, T_{1} z\right)+\delta^{p-m}\left(z, T_{2} z\right)=0$, then $T_{1} z=T_{2} z=\{z\}$. If $\delta^{p-m}\left(z, T_{1} z\right)+\delta^{p-m}\left(z, T_{2} z\right) \neq$ 0 , then, from (18), $T_{1} z=T_{2} z$. Substituting in the inequality for $H$ yields $H\left(T_{2} z, T_{2} y_{n}\right)=$ $H\left(T_{1} z, T_{2} y_{n}\right) \leq c^{1 / m} D\left(y_{n}, T_{2} y_{n}\right) \rightarrow 0$ as $n \rightarrow \infty$, and $T_{2}$ is continuous at $z$.

Similarly, $T_{1}$ is continuous at $z$.

Let $C(X)$ denote the nonempty compact subsets of $X$. A space $X$ is said to be $x_{o}$-jointly orbitally complete if every Cauchy sequence of each orbit at $x_{o}$ is convergent in $X$.

THEOREM 19. Let $F_{i}: X \rightarrow C(X), i=1,2, X x_{0}$-jointly complete for some $x_{0} \in X$. Suppose there exists a function $\psi:\left(\mathbf{R}^{+}\right)^{5} \rightarrow \mathbf{R}^{+}, \psi$ upper semicontinous and nondecreasing in each variable, such that

$$
\gamma(t):=\max \{\psi(t, t, t, t, t), \psi(t, t, 2 t, 0, t), \psi(t, t, 0,2 t, t)\}
$$


satisfies $\gamma(t)<t$ for each $t>0$. Suppose that the $F_{\mathfrak{z}}$ satisfy

$$
H\left(F_{1} x, F_{2} y\right) \leq \psi\left\{D\left(x, F_{1} x\right), D(y, F 2 y), D\left(x, F_{2} y\right), D\left(y, F_{1} x\right), d(x, y)\right\}
$$

for all $x, y$ in $X$. Then $F_{1}$ and $F_{2}$ have a common fixed point. Moreover $F_{1}$ and $F_{2}$ are continuous at each fixed point.

The existence of a fixed point is Theorem 2.1 of Guay et al [28]. To prove that $F_{1}$ is continuous at a fixed point $z$, let $\left\{y_{n}\right\} \subset X, y_{n} \rightarrow z$, and set $x=y_{n}, y=z$ in (19) to get

$$
H\left(F_{1} y_{n}, F_{2} z\right) \leq \psi\left\{D\left(y_{n}, F_{1} y_{n}\right), D\left(z, F_{2} z\right), D\left(y_{n} F_{2} z\right), D\left(z, F_{1} y_{n}\right), d\left(y_{n}, z\right)\right\}
$$

Thus

$$
D\left(F_{1} y_{n}, z\right) \leq \psi\left\{D\left(y_{n}, F_{1} y_{n}\right), 0, D\left(y_{n} F_{2} z\right), D\left(z, F_{1} y_{n}\right), d\left(y_{n} z\right)\right\} .
$$

Suppose that $\delta=\lim \sup D\left(F_{1} y_{n}, z\right)>0$. Since $D\left(y_{n}, F_{1} y_{n}\right) \leq D\left(y_{n}, z\right)+D\left(z, F_{1} y_{n}\right)$, $\limsup D\left(y_{n}, F_{1} y_{n}\right) \leq \limsup D\left(z, F_{1} y_{n}\right)$. Since $z \in F_{2} z, \lim \sup D\left(y_{n} F_{2} z\right)=0$. Therefore we have $\delta \leq \psi(\delta, 0,0, \delta, 0) \leq \psi(\delta, \delta, \delta, \delta, \delta)<\delta$, a contradiction. Consequently $\lim _{n} D\left(F_{1} y_{n}, z\right)=0$, and $\lim _{n} D\left(y_{n}, F_{1} y_{n}\right)=0$.

From (19) with $x=y=z$,

$$
H\left(F_{1} z, F_{2} z\right) \leq \psi\left\{D\left(z, F_{1} z\right), D\left(z, F_{2} z\right), D\left(z, F_{2} z\right), D\left(z, F_{1} z\right), d(z, z)\right\}=\psi(0,0,0,0,0)=0
$$

and $F_{1} z=F_{2} z$. Substituting in the inequality for $H$ we have

$$
H\left(F_{1} y_{n}, F_{1} z\right) \leq y\left\{D\left(y_{n}, F_{1} y_{n}\right), 0, D\left(y_{n}, F_{1} z\right), D\left(z, F_{1} y_{n}\right), d\left(y_{n}, z\right)\right\} .
$$

Taking the limsup as $n \rightarrow \infty$, yields $\lim \sup _{n} H\left(F_{1} y_{n}, F_{1} z\right) \leq \psi(0,0,0,0,0)=0$, and $F_{1}$ is continuous at $z$.

A similar argument verifies that $F_{2}$ is continuous at $z$.

THEOREM 20. Let $X$ be a complete metric space, $F_{n}: X \rightarrow C(X)$. Suppose that there exists a function $\psi$ satisfying the conditions of Theorem 19 and such that

$$
H\left(F_{i} x, F_{j} y\right) \leq \psi\left\{D\left(x, F_{i} x\right), D\left(y, F_{j} y\right), D(x, F, y), D\left(y, F_{i} x\right), d(x, y)\right\}
$$

for each $x, y$ in $X$, for each $i, j, i \neq j$. Then $\left\{F_{n}\right\}$ has a common fixed point, and each of the $F_{i}$ is continuous at this fixed point.

The existence of a common fixed point is Theorem 2.5 of Guay et al [28]. The continuity is proved in the same way as in Theorem 19.

Theorem 4 of Kaneko [19] is a special case of Theorem 20.

THEOREM 21. Let $(X, d)$ be a complete Hausdorff uniform space defined by $\left\{d_{\lambda}: \lambda \in I\right\}$. Let $F_{i}: X \rightarrow 2^{X}, i=1,2$ satisfying

$$
\left.H_{\lambda}\left(F_{1} x, F_{2} y\right) \leq a_{\lambda} d_{\lambda}\left(x, F_{1} x\right)+b_{\lambda} d_{\lambda}\left(y, F_{2} y\right)+c_{\lambda} d_{\lambda}\left(x, F_{2} y\right)+e_{\lambda} d_{\lambda}\left(y, F_{1} x\right)+f_{\lambda} d_{\lambda}(x, y)\right\}
$$

for each $x, y$ in $X$, where $a_{\lambda}, b_{\lambda}, c_{\lambda}, e_{\lambda}, f_{\lambda} \geq 0, a_{\lambda}+b_{\lambda}+c_{\lambda}+e_{\lambda}+f_{\lambda}<1$ and $a_{\lambda}=b_{\lambda}$ or $c_{\lambda}=e_{\lambda}$. Then $F_{1}$ and $F_{2}$ have a common fixed point. Also, $F_{1}$ and $F_{2}$ are continuous at each common fixed point. 
The proof that there is a common fixed point $z$ is Theorem 3.1 of Mishra [29]. To prove that $F_{1}$ is continuous at $z$, let $\left\{y_{n}\right\} \subset X, y_{n} \rightarrow z$, and set $x=y_{n}, y=z$ in (21) to get

$$
H_{\lambda}\left(F_{1} y_{n}, F_{2} z\right) \leq a_{\lambda} d_{\lambda}\left(y_{n}, F_{1} y_{n}\right)+b_{\lambda} d_{\lambda}\left(z, F_{2} z\right)+c_{\lambda} d_{\lambda}\left(y_{n}, F_{2} z\right)+e_{\lambda} d_{\lambda}\left(z, F_{1} y_{n}\right)+f_{\lambda} d_{\lambda}\left(y_{n}, z\right) .
$$

Since $d_{\lambda}\left(F_{1} y_{n}, z\right) \leq H_{\lambda}\left(F_{1} y_{n}, F_{2} z\right)$, the above inequality implies that

$$
d_{\lambda}\left(F_{1} y_{n}, z\right) \leq \frac{\left(a_{\lambda}+f_{\lambda}\right) d_{\lambda}\left(y_{n}, z\right)+c_{\lambda} d_{\lambda}\left(y_{n}, z\right)}{1-a_{\lambda}-b_{\lambda}} \rightarrow 0 \text { as } n \rightarrow \infty \text {. }
$$

It then follows that $\lim _{n} d_{\lambda}\left(y_{n}, F_{1} y_{n}\right)=0$. Setting $x=y=z$ in (21) yields $F_{1} z=F_{2} z$. Substituting in the inequality for $H$ gives

$$
H_{\lambda}\left(F_{1} y_{n}, F_{1} z\right) \leq a_{\lambda} d_{\lambda}\left(y_{n}, F_{1} y_{n}\right)+c_{\lambda} d_{\lambda}\left(y_{n}, F_{1} z\right)+e_{\lambda} d_{\lambda}\left(z, F_{1} y_{n}\right)+f_{\lambda} d_{\lambda}\left(y_{n}, z\right) .
$$

Taking the limit as $n \rightarrow \infty$ we obtain $\lim _{n} H_{\lambda}\left(F_{1} y_{n}, F_{1} z\right)=0$, and $F_{1}$ is continuous at $z$.

Similarly, $F_{2}$ is continuous at $z$.

The result in Mishra and Singh [30] is a special case of Theorem 3.1 of Mishra [29].

THEOREM 22. Let $X$ be a reflexive Banach space, $K$ a nonempty closed bounded convex subset of $X$. Let $T$ be a mapping of $K$ into the family of nonempty weakly compact convex subsets of $K$ satisfying

$$
H(T x, T y) \leq \phi(\max \{D(x, T x), D(y, T y)\}
$$

for each $x, y$ in $X$, where $\phi:[0, \infty) \rightarrow[0, \infty)$, nondecreasing, right continuous, such that $\phi(t)<t$ for each $t>0$. Then there exists a nonempty subset $M$ of $K$ such that $T x=M$ for each $x \in M$. Moreover, $T$ is continuous at each point of $M$.

The fact that a subset $M$ exists with the stated properties is Theorem 1 of Kaneko [31]. To prove the continuity of $T$, let $z \in M$. Let $\left\{y_{n}\right\} \subset X, y_{n} \rightarrow z$, and set $x=y_{n}, y=z$ in (22) to get

$$
H\left(T y_{n}, T z\right) \leq \phi\left(\max \left\{D\left(y_{n}, T y_{n}\right), D(z, T z)\right\}\right) .
$$

Thus $D\left(T y_{n}, z\right) \leq H\left(T y_{n}, T z\right) \leq \phi\left(D\left(y_{n}, T y_{n}\right)\right)$. Assume that $\delta=\lim \sup D\left(T y_{n}, z\right)>0$. Then we have $\delta \leq \phi\left(\lim \sup \left[D\left(y_{n}, z\right)+D\left(T y_{n}, z\right)\right]\right)=\phi(\delta)<\delta$, a contradiction. Therefore $\delta=0$ and $T$ is continuous at $z$.

THEOREM 23. Let $(X, d)$ be a complete metric space, $\left\{S_{n}\right\},\left\{T_{n}\right\}$ sequences of maps from $X \rightarrow C B(X)$. Suppose that there exists an $h, 0<h<1$, such that, for each $m, n$, and each $x, y$ in $X$,

$$
H\left(S_{m} x, T_{n} y\right) \leq h \max \left\{d(x, y), D\left(x, S_{m} x\right), D\left(y, T_{n} y\right),\left[\left(D x, T_{n} y\right)+D\left(y, S_{m} x\right)\right] / 2\right\} .
$$

Then $\left\{S_{m}\right\}$ and $\left\{T_{n}\right\}$ have a common fixed point $z$. Moreover, $\left\{S_{m}\right\}$ and $\left\{T_{n}\right\}$ are continuous at $z$.

The existence of a common fixed point $z$ is Theorem 1 of Kubiak [32]. To prove that each $S_{m}$ is continuous, let $\left\{y_{n}\right\} \subset X, y_{n} \rightarrow z$, and set $x=y_{k}, y=z$ in (23) to get

$$
H\left(S_{m} y_{k}, T_{n} z\right) \leq h \max \left\{d\left(y_{k}, z\right), D\left(y_{k}, S_{m} y_{k}\right), D\left(z, T_{n} z\right),\left[\left(D\left(y_{k}, T_{n} z\right)+D\left(z, S_{m} y_{k}\right)\right] / 2\right\}\right.
$$


Since $D\left(S_{m} y_{k}, z\right) \leq H\left(S_{m} y_{k}, T_{n} z\right)$, the above inequaltiy yields

$$
D\left(S_{m} y_{k}, z\right) \leq h d\left(y_{k}, z\right) /(1-h) \rightarrow 0 \text { as } k \rightarrow \infty .
$$

It then follows that $\lim _{k} D\left(y_{k}, S_{m} y_{k}\right)=0$.

Setting $x=y=z$ in (23) gives the result that $S_{m} z=T_{n} z$. Substituting in the inequality for $H$ yields

$$
H\left(S_{m} y_{k}, S_{m} z\right) \leq h \max \left\{d\left(y_{k}, z\right), D\left(y_{k}, S_{m} y_{k}\right), 0,\left[\left(D\left(y_{k}, S_{m} z\right)+D\left(z, S_{m} y_{k}\right)\right] / 2\right\}\right.
$$

and, taking the limit as $k \rightarrow \infty$ gives $\lim _{k} H\left(S_{m} y_{k}, S_{m} z\right)=0$, and each $S_{m}$ is continuous at $z$.

A similar argument verifies that each $T_{n}$ is continuous at $z$.

Special cases of Theorem 1 of Kubiak [32] appear in Avram [33], Iseki [21], Popa [34 - 35], Ray [36], Rus [37], and Wong [38]. Achara [39] has the same result as Kubiak [32], but with $C B(X)$ replaced by $C(X)$.

THEOREM 24. Let $(X, d)$ be a complete metric space, $T_{n}: X \rightarrow C B(X)$. Suppose that there exist $\alpha_{\imath} \geq 0, i=1, \ldots, 5$ such that

$$
\min \left\{\alpha_{1}+\alpha_{2}+\alpha_{3}+2 \alpha_{4}, \alpha_{1}+\alpha_{2}+\alpha_{3}+2 \alpha_{5}\right\}<1
$$

and $m \neq n$ implies

$$
H\left(T_{m} x, T_{n} y\right) \leq \alpha_{1} d(x, y)+\alpha_{2} D\left(x, T_{m} x\right)+\alpha_{3} D\left(y, T_{n} y\right)+\alpha_{4} D\left(x, T_{n} y\right)+\alpha_{5} D\left(y, T_{m} x\right)
$$

for all $x, y$ in $X$. Then $\left\{T_{n}\right\}$ has a common fixed point.

The proof that the $\left\{T_{n}\right\}$ has a common fixed point is Theorem 1 of Kita [40]. To prove continuity, let $z$ be a comon fixed point of $\left\{T_{n}\right\}$, and let $\left\{y_{n}\right\} \subset X, y_{n} \rightarrow z$.

Suppose that $\alpha_{4}<\alpha_{5}$. Then $\min \left\{\alpha_{1}+\alpha_{2}+\alpha_{3}+2 \alpha_{4}, \alpha_{1}+\alpha_{2}+\alpha_{3}+2 \alpha_{5}\right\}=\alpha_{1}+\alpha_{2}+\alpha_{3}+2 \alpha_{4}<1$.

Set $x=z, y=y_{k}$. From (24),

$$
H\left(T_{m} z, T_{n} y_{k}\right) \leq \alpha_{1} d\left(z, y_{k}\right)+\alpha_{2} D\left(z, T_{m} z\right)+\alpha_{3} D\left(y_{k}, T_{n} y_{k}\right)+\alpha_{4} D\left(z, T_{n} y_{k}\right)+\alpha_{5} D\left(y_{k}, T_{m} z\right),
$$

or, since $D\left(z, T_{n} y_{k}\right) \leq H\left(T_{m} z, T_{n} y_{k}\right)$, we obtain

$$
D\left(z, T_{n} y_{k}\right) \leq \frac{\left(\alpha_{1}+\alpha_{3}\right) d\left(z, y_{k}\right)+\alpha_{5} D\left(y_{k}, T_{m} z\right)}{1-\alpha_{3}-\alpha_{4}} \rightarrow 0 \text { as } k \rightarrow \infty .
$$

Thus $\lim _{k} D\left(z, T_{n} y_{k}\right)=0$, which implies that $\lim _{k} D\left(y_{k}, T_{n} y_{k}\right)=0$.

Substituting $x=y=z$ into (24) verifies that $T_{m} z=T_{n} z$. It then follows that

$$
H\left(T_{n} z, T_{n} y_{k}\right)=H\left(T_{m} z, T_{n} y_{k}\right) \leq \alpha_{1} d\left(z, y_{k}\right)+\alpha_{3} D\left(y_{k}, T_{n} y_{k}\right)+\alpha_{4} D\left(z, T_{n} y_{k}\right)+\alpha_{5} D\left(y_{k}, T_{m} z\right) .
$$

Taking the limit as $k \rightarrow \infty$ yields the result that each $T_{n}$ is continuous at $z$.

If $\alpha_{4} \geq \alpha_{5}$, then, setting $x=y_{k}, y=z$ in (24) yields

$$
D\left(T_{m} y_{k}, z\right) \leq \frac{\left(\alpha_{1}+\alpha_{2}\right) d\left(z, y_{k}\right)+\alpha_{4} D\left(y_{k}, T_{m} z\right)}{1-\alpha_{3}-\alpha_{5}} \rightarrow 0 \text { as } k \rightarrow \infty .
$$

from which it follows that each $T_{m}$ is continuous at $z$. 
Although we have experienced some success with establishing the continuity of multivalued maps at a fixed point, there are some definitions that do not lend themselves to such an analysis. We cite here three examples.

THEOREM K. (Khan and Kubiaczyk [41], Theorem 1) Let $S, T,: X \rightarrow B(X)$ be such that, for some $\phi \in \Phi:=\left\{\phi:\left(\mathbf{R}^{+}\right) 5 \rightarrow \mathbf{R}^{+}:\right.$is upper semicontinuous from the right, nondecreasing in each variable coordinate such that $\phi(t, t, t, a t, b t)<t$ for each $t>0, a, b \geq 0$, with $a+b \leq 2\}$,

$$
\delta(S x, T y) \leq \phi(d(x, y), \delta(x, S x), \delta(y, T y), D(x, T y), D(y, T x)
$$

for each $x, y$ in $X$. Then $S$ and $T$ have a unique common fixed point $u$ such that $u \in S u \cap T u$.

In the above theorem the difficulty arises from the fact that $\delta(u, T u)$ need not be zero.

THEOREM M. (Mukherjee and Som [42], Theorem 1 ) Let $(X, d)$ be a complete metric space, $T_{1}, T_{2}: X \rightarrow C B(X)$ satisfying any one of the following conditions for each $x, y$ in $X$ :

(i) $\delta\left(x, T_{1} x\right)+\delta\left(y, T_{2} y\right) \leq a d(x, y), 1 \leq \alpha<2$,

(ii) $\delta\left(x, T_{1} x\right)+\delta\left(y, T_{2} y\right) \leq \beta\left\{\left(x, T_{2} y\right)+H\left(y, T_{2} x\right)+d(x, y)\right\}, 1 / 2<\beta<2 / 3$,

(iii) $\delta\left(x, T_{1} x\right)+\delta\left(y, T_{2} y\right)+\delta\left(T_{1} x, T_{2} y\right) \leq \gamma\left\{H\left(x, T_{2} y\right)+H\left(y, T_{1} x\right)\right\}, 1 \leq \gamma<3 / 2$,

(iv) $\delta\left(T_{1} x, T_{2} y\right) \leq \eta \max \left\{d(x, y), H\left(x, T_{1} x\right), H\left(y, T_{2} y\right),\left[H\left(x, T_{2} y\right)+H\left(y, T_{1} x\right)\right] / 2\right\}, 0 \leq \eta<1$.

Then $T_{1}$ and $T_{2}$ have a common fixed point.

THEOREM S. (Singh et al [43], Theorem 2.1) Let $S, T$, be multivalued mappings from a metric space $X \rightarrow C L(X)$. If there exists a function $f: X \rightarrow X$ such that $S X \cup T X \subseteq f(X)$ and, for each $x, y$ in $X$,

$$
H(S x, T y) \leq \phi(\max \{D(f x, S x), D(f y, T y), D(f x, T y), D(f y, S x), d(f x, f y)\})
$$

where $\phi: \mathbf{R}^{+} \rightarrow \mathbf{R}^{+}, \phi$ upper semicontinuous and nondecreasing with $\phi(t)<t$ for each $t>0$, there exists a point $x_{0}$ in $X$ such that $(S, T)$ is asymptotically regular at $x_{0}$ and $f(x)$ is $\left(S, T ; f, x_{0}\right)$-orbitally complete, then $f, S$, and $T$ have a coincidence point. Further, if $z$ is a coincidence point of $f, S, T$, and $f z$ is a fixed point of $f$, then

(a) $f z$ is a fixed point of $S(\operatorname{resp} T)$ provided $f$ commutes weakly with $S(\operatorname{resp} T)$ at $z$, and

(b) $f z$ is a common fixed point of $S$ and $T$ at $z$.

ADDED IN PROOF. 1. A closer examination of the proof of Theorem $K$ shows that $\delta(u, S u)=\delta(u, T u)=0$. Therefore an argument similar to the one already used repeatedly in this paper yields that $S$ and $T$ are continuous at the fixed point.

2. Theorem $M$ contains an error in the proof. Moreover, conditions (i) and (ii) imply that $T_{1} x=T_{2} x=\{x\}$ for each $x$ in $X$. The parameter values on conditions (iii) and (iv) make it impossible to use standard proof techniques to obtain a fixed point.

3. If one assumes the continuity of $f$ in Theorem $S$, then it is straightforward to verify that $S$ and $T$ are continuous at the fixed point $f z$. 


\section{REFERENCES}

1. RHOADES, B. E. Contractive definitions and continuity, Contemporary Math. 72 (1988), 233-245.

2. FISHER, B. Fixed points of mappings and set-valued mappings. J. Univ. Kuwait 9 (1982), 175-179.

3. FISHER, B. Set-valued mappings on metric spaces. Fund. Math. 12 (1981), 141-145.

4. FISHER, B. Fixed points for set-valued mappings on metric spaces. Bull. Malaysian Math. Soc. 4 (1981), 95-99.

5. MENDAGLIO, V. and DUBE, L. S. On fixed points of multi- valued mappings. Bull. Math. Roumaine 25 (1981), 167-170.

6. SAMANTA, A. and BAISNAB, A. P. Fixed point theorems for set valued mappings. Bull. Calcutta Math. Soc. 79 (1987), 207-214.

7. DIXIT, S. P. A fixed point theorem for set-valued mappings. Bull. Calcutta Math. Soc. 77 (1985), 165-169.

8. FISHER, B. Set-valued mappings on bounded metric spaces. Indian J. Pure and Appl. Math. 11 (1980), 8-12.

9. FISHER, B. Common fixed points of set-valued mappings on bounded metric spaces. Math. Seminar Notes 11 (1983), 307-311.

10. FISHER, B. A result on fixed points for set-valued mappings. Iraqi J. Sci. 21 (1980), 464-469.

11. FISHER, B. Common fixed point theorems for mappings and set-valued mappings. J. Univ. Kuwait 11 (1984), 15-21.

12. FISHER, B. Common fixed points for set-valued mappings, Indian J. Math. 25 (1983), 265-270.

13. FISHER, B. Common fixed points of mappings and set-valued mappings on metric spaces. Kyungpook Math. J. 25 (1985), 35-42.

14. FISHER, B. Common fixed points of set-valued mappings, Punjab Univ. J. of Math. 14-15 (1981-82), 155-164.

15. GAREGNANI, G. and MASSA, S. Multi-valued mappings of contractive type, Istit. Lombardo Accad Sci. Rend. 112 (1978), 283-288.

16. SINGH, S.L.S and KULSHRESTHA, C. Coincidence theorems in metric spaces, Indian J. Phys. Nat. Sci. B2 (1982), 19-22.

17. CIRIC, L. J. Fixed points for generalized multi-valued contractions, Mat. Vesnik $9(234)$ (1972), 265-272.

18. REICH, S. Kannan's fixed point theorems, Boll. UMI 4 (1971), 1-11.

19. KANEKO, $\mathrm{H}$. A comparison of contractive conditions for multi-valued mappings, Math. 3 (1986), 37-45.

20. CZERWICK, S. Multi-valued contraction mappings in metric spaces, Aeq. Math. 16 (1977), 297-302.

21. ISEKI, K. Multi-valued contraction mappings in complete metric spaces, Rend. Sem. Mat. Univ. Padova 53 (1975), 15-19.

22. RAY, Barada K. Some fixed point theorems, Nanta Math. 8 (1975), 9-20.

23. ITOH, S. Multivalued generalized contractions and fixed point theorems, Comment. Math. Univ. Carolinae 18 (1977), 247-258.

24. BOSE, R.K. and MUKHERJEE, R. N. Common fixed points of some multivalued mappings, Tamkang J. Math. 81 (1977), 245-249.

25. KHAN, M.S. Common fixed point theorems for multivalued mappings, Pacific J. Math. 95 (1981), 337-347. 
26. POPA, V. Fixed point theorems for a sequence of multifunctions, Bull. Math. Soc. Stiinte Rom. 28 (1984), 251-257.

27. POPA, V. Common fixed points for multifunctions satisfying a rational inequality, Kobe J. Math. 2 (1985), 23-28.

28. GUAY, M.D., SINGH, K.L., and WHITFIELD, J.H.M. Common fixed points for setvalued mappings, Bull de L'Acad Pol. des Sci. 30 (1982), 545-551.

29. MISHRA, S.N. A note on common fixed points of multivalued mappings in uniform spaces, Math. Sem. Notes 9 (1981), 341-347.

30. MISHRA, S.N. and SINGH, S.L. Fixed point of multivalued mappings in uniform spaces, Bull. Calcutta Math. Soc. 77 (1985), 323-329.

31. KANEKO, H. A report on general contractive type conditions for multivalued mappings. Math. Japonica 4 (1988), 57-64.

32. KUBIAK, T. Fixed point theorems for contractive type multivalued mappings, Math. Japonica 109 (1985), 89-101.

33. AVRAM, M. Points fixes communs pour les applications multivoques dans les espaces metriques, Math. Cluj. 17 (1975), 153-156.

34. POPA, V. A common fixed point theorem for a sequence of multifunctions, Studia Univ. Babes-Bolyai Math. 24 (1979), 39-41.

35. POPA, V. Puncte fixe comune pentru un sire de multifunctii, Stud. Cerc. Mat. 34 (1982), 370-373.

36. RAY, Barada K. A note on multi-valued contraction mappings, Atti Accad Naz. Lincei 56 (1974), 500-503.

37. RUS, I. Fixed point theorems for multi-valued mappings in complete metric spaces, Math. Japonica 25 (1975), 21-24.

38. WONG, C.S. Common fixed points of two mappings, Pacific J. Math. 48 (1975), 299-312.

39. ACHARA, J. Generalized multi-valued contractions and fixed points, Revue Romaine de Math. Pures et Appl. 24 (1979), 178-182.

40. KITA, T. A common fixed point theorems for multivalued mappings, Math. Japonica 22 (1979), 113-116.

41. KHAN, M.S. and KUBIACZYK, I. Fixed point theorems for point to set maps, Math. Japonica 33 (1988), 409-415.

42. MUKHERJEE, R.N. and SOM, T. On some fixed point theorems for generalized multivalued mappings, Indian J. Pure Appl. Math. 14 (1983), 1506-1509.

43. SINGH, S.L., HA, K.S., and CHO, Y.S. Coincidence and fixed points of nonlinear hybrid contractions, Int. J. Math. and Math. Sci. 12 (1989), 247-256. 


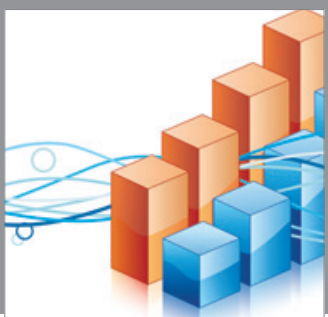

Advances in

Operations Research

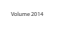

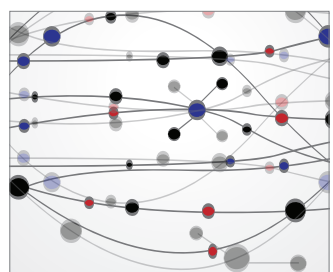

\section{The Scientific} World Journal
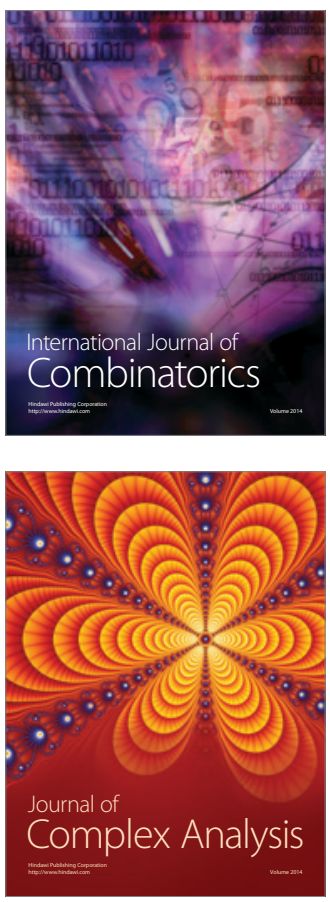

International Journal of

Mathematics and

Mathematical

Sciences
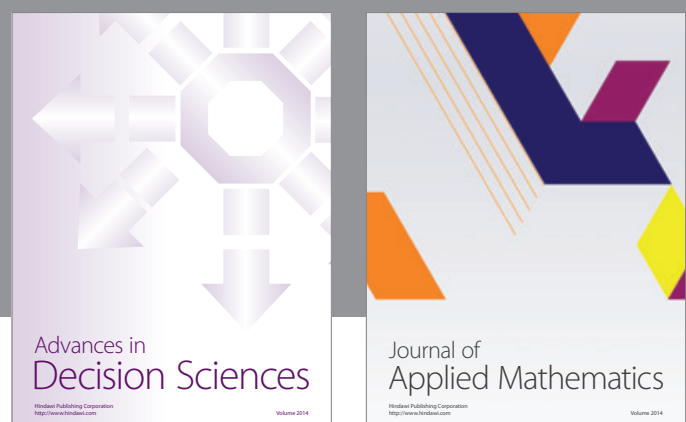

Journal of

Applied Mathematics
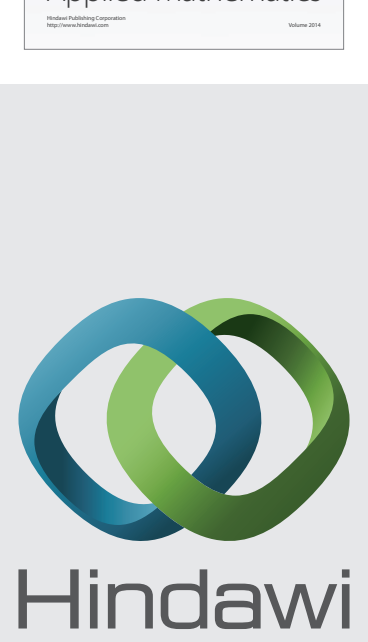

Submit your manuscripts at http://www.hindawi.com
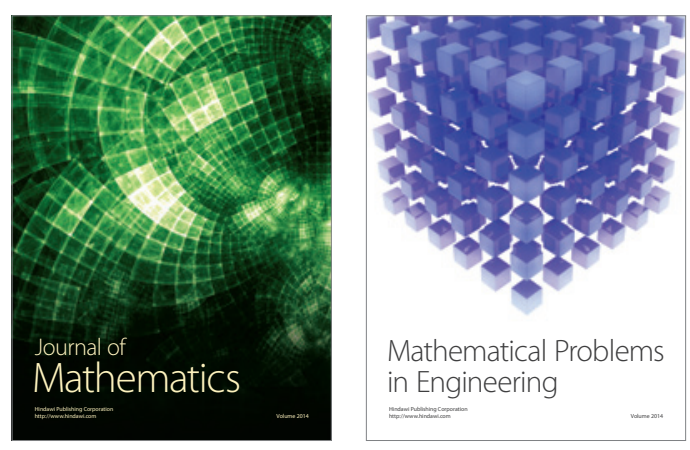

Mathematical Problems in Engineering
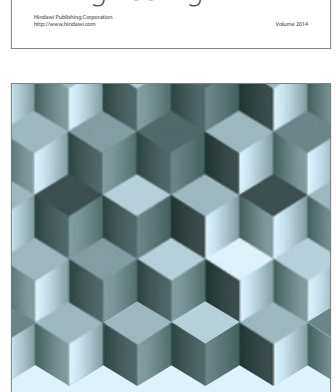

Journal of

Function Spaces
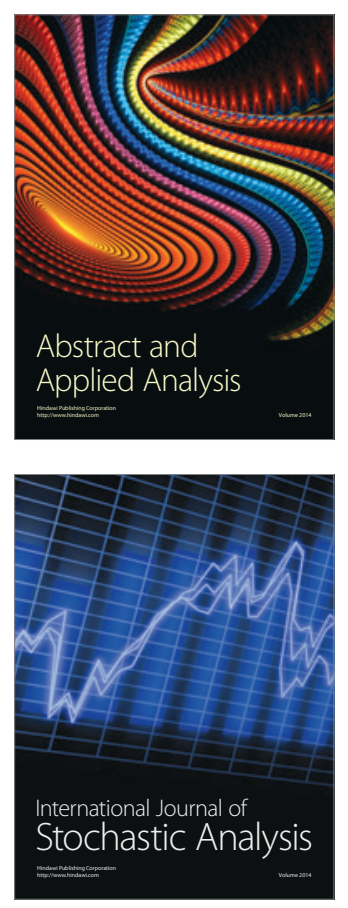

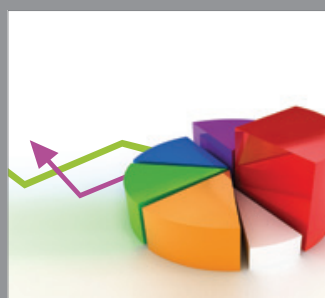

ournal of

Probability and Statistics

Promensencen
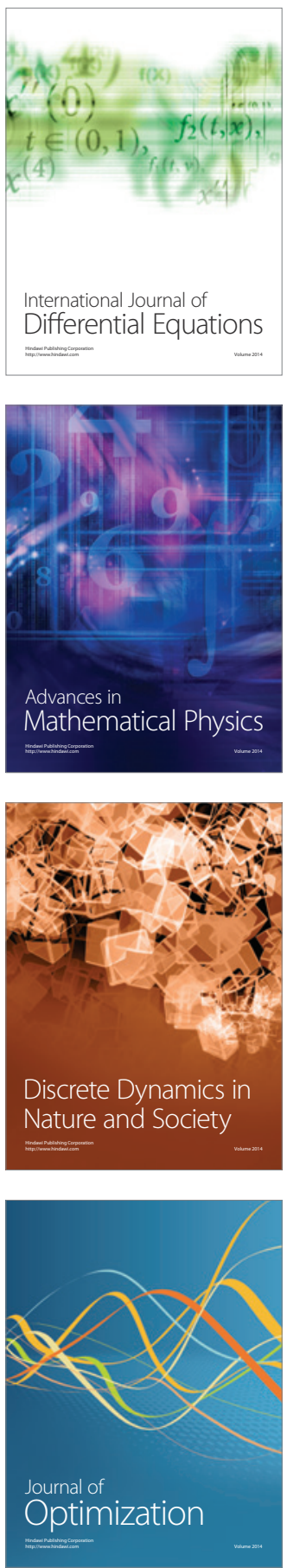